\title{
No way out? The double-bind in seeking global prosperity alongside mitigated climate change
}

\author{
T. J. Garrett \\ Department of Atmospheric Sciences, University of Utah, Salt Lake City, Utah, USA
}

Correspondence to: T. J. Garrett (tim.garrett@utah.edu)

Received: 21 March 2011 - Published in Earth Syst. Dynam. Discuss.: 6 April 2011

Revised: 3 December 2011 - Accepted: 31 December 2011 - Published: 5 January 2012

\begin{abstract}
In a prior study (Garrett, 2011), I introduced a simple economic growth model designed to be consistent with general thermodynamic laws. Unlike traditional economic models, civilization is viewed only as a well-mixed global whole with no distinction made between individual nations, economic sectors, labor, or capital investments. At the model core is a hypothesis that the global economy's current rate of primary energy consumption is tied through a constant to a very general representation of its historically accumulated wealth. Observations support this hypothesis, and indicate that the constant's value is $\lambda=9.7 \pm 0.3$ milliwatts per 1990 US dollar. It is this link that allows for treatment of seemingly complex economic systems as simple physical systems. Here, this growth model is coupled to a linear formulation for the evolution of globally well-mixed atmospheric $\mathrm{CO}_{2}$ concentrations. While very simple, the coupled model provides faithful multi-decadal hindcasts of trajectories in gross world product (GWP) and $\mathrm{CO}_{2}$. Extending the model to the future, the model suggests that the well-known IPCC SRES scenarios substantially underestimate how much $\mathrm{CO}_{2}$ levels will rise for a given level of future economic prosperity. For one, global $\mathrm{CO}_{2}$ emission rates cannot be decoupled from wealth through efficiency gains. For another, like a long-term natural disaster, future greenhouse warming can be expected to act as an inflationary drag on the real growth of global wealth. For atmospheric $\mathrm{CO}_{2}$ concentrations to remain below a "dangerous" level of 450 ppmv (Hansen et al., 2007), model forecasts suggest that there will have to be some combination of an unrealistically rapid rate of energy decarbonization and nearly immediate reductions in global civilization wealth. Effectively, it appears that civilization
\end{abstract}

may be in a double-bind. If civilization does not collapse quickly this century, then $\mathrm{CO}_{2}$ levels will likely end up exceeding 1000 ppmv; but, if $\mathrm{CO}_{2}$ levels rise by this much, then the risk is that civilization will gradually tend towards collapse.

\section{Introduction}

Despite decades of public awareness of the potential for fossil fuel consumption to lead to dangerous climate change, anthropogenic emissions of $\mathrm{CO}_{2}$ have accelerated (Canadell et al., 2007; Raupach et al., 2007). The implications of civilization continuing on this path are environmental changes that are both irreversible and profound, including amplified hydrological extremes, storm intensification, sea level rise, and extreme mammalian heat stress (Hansen et al., 2007; Allan and Soden, 2008; Solomon et al., 2009; Vermeer and Rahmstorf, 2009; Sherwood and Huber, 2010).

The economic costs associated with addressing and coping with climate warming are normally quantified by coupling a system of economic equations to a medium complexity climate model. Normally, these Integrated Assessment Models (IAMs) make regionally-based assessments of the economics of production, investment, consumption, welfare, discount rates, population and rates of technological change. These economic functions are coupled to functions for atmospheric temperature and climate damage. From within a parameter space that might be of order 100 variables, the model outcome is a long-term optimized trajectory for longterm societal welfare to which policy measures (for example 


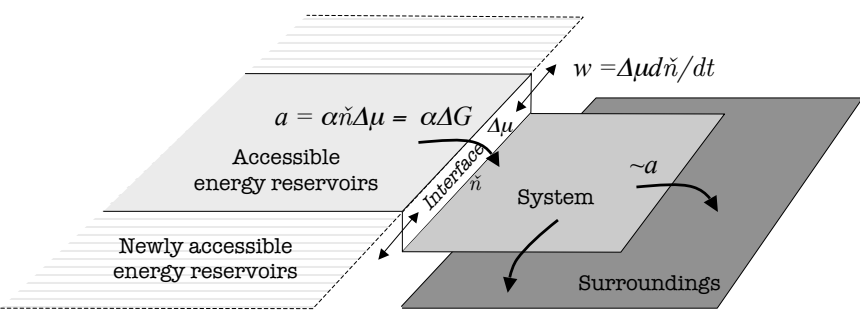

Thermodynamic

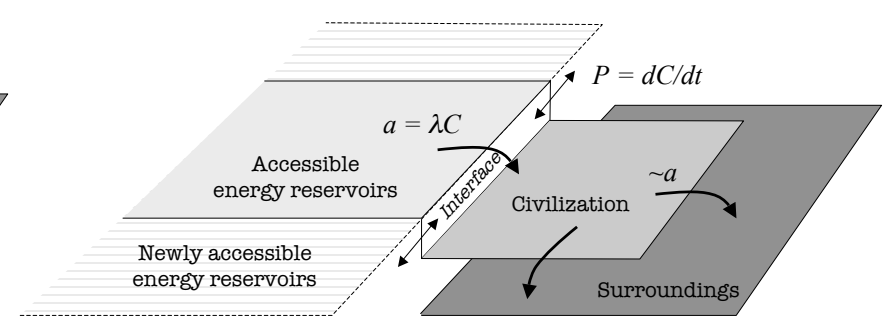

Economic

Fig. 1. Schematic for the thermodynamic evolution of an open system, and its hypothesized economic representation. Energy reservoirs, civilization, and its surroundings lie along distinct constant potential surfaces. The number of material units $\breve{n}$ defining an interface between civilization and energy reservoirs determines the speed of downhill energetic flow at rate $a$, in proportion to a fixed specific potential difference $\Delta \mu$ and rate coefficient $\alpha$. The interface itself grows or shrinks at rate $w$ due to a net flux convergence into civilization. In a positive feedback, interface growth at rate $d \breve{n} / d t$ expands energetic flows $a$ by extending civilization's access to previously inaccessible energy reservoirs at rate $d a / d t$. Fiscally, wealth $C$ is proportional to both the interface size $\breve{n}$ and the rate of primary energy consumption $a$. The GWP $P$ represents the net expansion of wealth at rate $d C / d t$ due to interface growth. $C$ and $a$ are linked through a constant $\lambda$. See the text and Garrett (2011) for details.

the Copenhagen Accord) can be compared (Nordhaus and Boyer, 2000; Keller et al., 2004; Nordhaus, 2010). Uncertainty in the optimal path, when addressed, is modeled using Monte Carlo simulations within a portion of the total parameter space (Mastrandrea and Schneider, 2004).

Modern IAMs are normally based on mainstream neoclassical economic growth models that, unlike climate models, do not explicitly represent flows as a material flux down pressure gradients. Economic flows are allowed to become progressively decoupled from energy consumption and $\mathrm{CO}_{2}$ emissions through gains in energy efficiency. Several of the widely used IPCC SRES scenarios even go so far as to allow economic growth to continue while $\mathrm{CO}_{2}$ emissions stabilize or decline (Raupach et al., 2007).

This "have our cake and eat it too" viewpoint has been disputed by many ecological economists. The argument against decoupling is that consumption of energy is thermodynamically required for any system to evolve, and there is no physical reason that the human system should be treated as an exception (Lotka, 1922; Georgescu-Roegen, 1993; Ayres et al., 2003). Some have even suggested that policies aimed at improving energy efficiency might backfire through what is known as "Jevons' Paradox": energy is useful, and for a given level of resource availability, efficiency gains make it cheaper and more desirable, ultimately leading to greater rates of energy consumption and $\mathrm{CO}_{2}$ emissions (Saunders, 2000; Alcott, 2005; Owen, 2010; Alcott, 2010).

This article continues in a similar conceptual vein, but it differs by treating the human system in a more strictly physical fashion. Here, no internal resolution is made of political divisions or economic sectors. Rather, civilization is treated only as a whole since internal economic trade and atmospheric mixing of $\mathrm{CO}_{2}$ are very rapid compared to the multi-decadal evolution of civilization. Further, no explicit account is made of people or their policies. Civilization is part of the physical universe and it is modeled as any other physical system. Long-term growth in global consumption and emission rates are considered only as a thermodynamic response to civilization's expansion into newly available energy resources.

Thus, unlike IAMs, this article does not evaluate what long-term policy actions will enable us to limit $\mathrm{CO}_{2}$ emissions while maximizing global economic wealth. Rather, the aim is to explore the range of future trajectories that is actually physically possible: political will can only go as far as physical laws allow. The argument that will be presented is that, unfortunately, wealth cannot be decoupled from resource consumption. In fact, at least at the global scales that are relevant to $\mathrm{CO}_{2}$ emissions, it appears that "Jevons' Paradox" does indeed apply: efficiency gains will backfire. For this reason, it is likely that all SRES scenarios considerably overestimate the extent of economic health that is possible for a given future atmospheric concentration of $\mathrm{CO}_{2}$. Either global warming acts as an inflationary drag on the production of wealth; or, economic growth is sustained and atmospheric $\mathrm{CO}_{2}$ concentrations accelerate their growth.

\section{A physically consistent economic framework}

An earlier article introduced a simple macroeconomic growth model that treats civilization in a manner consistent with physical conservation laws (Garrett, 2011). As illustrated in Fig. 1, all material within civilization is treated as being in local thermodynamic equilibrium with the same specific potential energy per unit matter; effectively, it is treated as a surface defined by constant temperature and pressure, constant density, or constant specific entropy. Accordingly, no distinction is made between the internal components of civilization. Unlike traditional economic models, no explicit 
account is made for labor, capital, households, firms, governments or banks, nor the flows to and from these components. Rather, civilization is considered only as a whole, or at a sufficiently low resolution that the only resolved distinction is between civilization and known primary energy reservoirs (e.g. coal, oil, uranium, etc.).

Flows to civilization can be viewed as a special case within the more general thermodynamic model shown in Fig. 1, a perspective that bears some similarities with the thermodynamic model used by Annila and Salthe (2009) to represent economic flows. Energy reservoirs lie along a higher potential surface than the system of interest. The interface that separates these two surfaces is defined by a fixed step in specific potential energy $\Delta \mu$ (units potential energy per material unit) and a number of material units defining the length of the interface $\breve{n}$. The total potential difference that is available to drive downward flows is the product of these two quantities, i.e. $\Delta G=\breve{n} \Delta \mu$. The flow redistributes the overall balance of potential energy towards the lower potential surface. Total material is conserved as required by the First Law of Thermodynamics, and the flow is downhill as required by the Second Law of Thermodynamics. The flow represents a "heating" of the lower potential system. The heating sustains this open system against a nearly equal dissipative flow due to the loss of energy to the system's surroundings.

For civilization, the heating is equivalent to the rate $a$ (units energy per time) at which civilization consumes the potential energy in primary energy resources. The flow rate of energy is proportional to the material length of the interface $\breve{n}$ through

$a=\alpha \Delta G=\alpha \breve{n} \Delta \mu$

where, $\alpha$ is a constant rate coefficient with units inverse time (effectively a diffusivity). This consumption of potential energy is more precisely defined as a material flux. For civilization, coal and oil are examples of the agents that carry the potential energy we consume. However, civilization is not made of coal and oil, but rather of raw materials such as iron and copper. Potential energy consumption enables these raw materials to be carried downward along with the energetic flow to add to civilization's material bulk and sustain it against decay.

If civilization's economic activities are part of the physical universe, then perhaps there might be a fiscal representation for the physical flows that sustain it. A hypothesis can be proposed that the size of civilization is expressible thermodynamically by the potential difference $\Delta G$ driving flows, or equivalently the heating of civilization at rate $a=\alpha \Delta G$. Since heating sustains all of civilization's activities against its ultimate dissipative loss to its surroundings, the heating rate might conceivably be what civilization intrinsically values, and therefore it might be related to a very general expression of civilization's real, or inflation-adjusted economic wealth through

$a \equiv \lambda C$ where the rate of consumption of the potential energy in primary energy resources $a$ (units energy per time) is related through a constant parameter $\lambda$ to a fiscal representation of global economic wealth $C$ (units inflation-adjusted currency). If there is no energy consumption, then civilization is worthless because the activities that sustain civilization's value cannot be maintained against civilization's energy loss through decay. Effectively civilization becomes indistinguishable from its surroundings because the interface $\breve{n}$ and the gradient $\Delta G$ shrink to zero. We eat to sustain ourselves against radiative heat loss. If we do not eat, eventually we die.

Here, wealth $C$ is defined as the historical accumulation of gross world economic real production $P$ (units inflationadjusted currency per time). A comparison of this definition with more traditional approaches is presented in Sect. 4. Here, real production $P$ is an instantaneous quantity that is related to the familiar gross world product (GWP) through

$\mathrm{GWP}=P \Delta t$

where, for the sake of economic statistics, $\Delta t$ is normally equal to one year. Total economic wealth is distinct from production in that it is not a differential but an integral quantity (units inflation-adjusted currency). As wealth is defined here, it is represented by the historical accumulation of production

$C \equiv \int_{0}^{t} P\left(t^{\prime}\right) d t^{\prime} \simeq \sum_{i} \mathrm{GWP}(i)$

where $i$ is an index covering the full historical record for GWP. Equivalently, economic production is a consequence of a convergence of the material and energetic flows associated with wealth

$\frac{d C}{d t} \equiv P$

or, expressed thermodynamically, from Eqs. (1) and (2)

$P=\frac{1}{\lambda} \frac{d a}{d t}=\Delta \mu \frac{\alpha}{\lambda} \frac{d \breve{n}}{d t}$.

Effectively, economic production $P$ is a fiscal representation of the growth rate of energy consumption $d a / d t$ through an expansion of civilization's material interface $\breve{n}$ into the primary energy reservoirs that it consumes. Combining Eqs. (4) and (6), global wealth arises from an accumulation of a net material convergence over time:

$C \equiv \frac{1}{\lambda} \int_{0}^{t} \frac{d a}{d t} d t^{\prime}=\Delta \mu \frac{\alpha}{\lambda} \int_{0}^{t} \frac{d \breve{n}}{d t} d t^{\prime}$.

Equations (1) and (2) imply a direct proportionality between wealth $C$, rates of primary energy consumption $a$, and the size of the interface driving flows $\Delta G=\breve{n} \Delta \mu$. In this case, there is a rate of return $\eta$ that applies equally to each:

$\eta \equiv \frac{d \ln \Delta G}{d t}=\frac{d \ln \breve{n}}{d t}=\frac{d \ln a}{d t}=\frac{d \ln C}{d t}$. 
Table 1. Measured values for the global rate of energy consumption $a$ (TW), global wealth $C$ (trillion 1990 US $\$$ ), $\mathrm{CO}_{2}$ emissions rates $E$

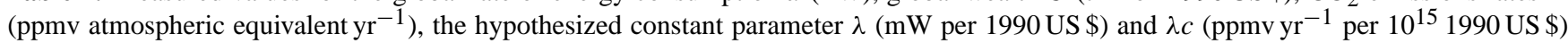
where $c=E / a$.

\begin{tabular}{lrrrrrrrrr}
\hline & 1970 & 1975 & 1980 & 1985 & 1990 & 1995 & 2000 & 2005 & 2008 \\
\hline$a(\mathrm{TW})$ & 7.2 & 8.4 & 9.6 & 10.3 & 11.7 & 12.2 & 13.2 & 15.3 & 16.4 \\
$C=\int_{0}^{t} P\left(t^{\prime}\right) d t^{\prime}$ & 821 & 884 & 960 & 1048 & 1151 & 1266 & 1398 & 1536 & 1656 \\
$\lambda=a / C$ & 8.8 & 9.4 & 10.0 & 9.8 & 10.2 & 9.6 & 9.4 & 9.9 & 9.9 \\
$E$ & 1.91 & 2.17 & 2.50 & 2.56 & 2.88 & 2.99 & 3.16 & 3.74 & 4.00 \\
$\lambda c=E / C$ & 2.3 & 2.4 & 2.6 & 2.4 & 2.5 & 2.4 & 2.3 & 2.4 & 2.4 \\
\hline
\end{tabular}

Positive values of $\eta$ allow for exponential growth associated with interface expansion. Civilization wealth and energy consumption are in exponential decay if the interface $\breve{n}$ shrinks.

Thus, from Eqs. (5) and (8), the economic production function for this framework is

$P \equiv \frac{d C}{d t}=\eta C$.

The rate of return $\eta$ (units inverse time) is a time varying quantity that relates the past accumulation of wealth $C$ to the current production of new wealth $P$. Finally, by taking the time derivative of Eq. (9), the GWP growth rate is given by

$\frac{d \ln P}{d t}=\eta+\frac{d \ln \eta}{d t}$.

Thus, what is normally termed as "economic growth" (i.e. $d \ln P / d t)$ is related to the sum of the growth rate of energy consumption $\eta$ and the acceleration of growth in energy consumption $d \ln \eta / d t$. The economic growth rate stalls if this acceleration stagnates.

\section{Model validation}

The above discussion rests on an assumed constancy of the parameter $\lambda$, as it is defined through Eqs. (2) and (4) by

$\lambda \equiv \frac{a(t)}{\int_{0}^{t} P\left(t^{\prime}\right) d t^{\prime}} \simeq \frac{a(t)}{\sum_{i} \operatorname{GWP}(i)}$.

To evaluate the validity of a hypothetical constancy of $\lambda$ in Eq. (11), I employed statistics for world GWP spanning more than 2000 years (Maddison, 2003; United Nations, 2010) to calculate wealth $C$ from Eq. (4). Values of $C$ were compared to nearly four decades of statistics for energy consumption rates $a$ (AER, 2009).

Details are described in Appendix C of Garrett (2011). As illustrated in Table 1, the comparison supports the hypothesis that the value of $\lambda$, as defined by Eq. (11), is indeed a constant that is independent of time: energy consumption rates $a$ and wealth $C=\int_{0}^{t} P d t^{\prime}$ both approximately doubled in tandem between 1970 and 2008. On a millennial scale this time interval is short, but it covers a tripling of GWP and more than half of total civilization growth. The full yearly time series indicates that, during this period, $\lambda$ maintained a mean value, with associated $95 \%$ confidence uncertainty in the mean, of $9.7 \pm 0.3$ milliwatts per 1990 US dollar (Garrett, 2011).

A theoretically equivalent approach to calculating $\lambda$ is to take the respective derivatives of $a$ and $C$ in order to compare the inter-annual change in energy consumption rates $d a / d t$ to the real GWP $P$ (Eq. 6). Derivatives of measured quantities are always more noisy than their integrals. For example, the magnitude of $d \ln a / d t$ is only about a couple of percent per year, where $a$ itself is subject to measurement uncertainties that, while unpublished, are plausibly of a similar magnitude. Nonetheless, the calculated mean value of $P /(d a / d t)$ for the 1970 to 2008 period is $11.6 \pm 4.1$ milliwatts per $1990 \mathrm{US}$ dollar, which is statistically consistent with the derived value for $\lambda \equiv a / C$ of $9.7 \pm 0.3$ milliwatts per 1990 US dollar.

This combination of theoretical and observational support for there being a fixed relationship between $C$ and $a$ is the key result supporting this study. It serves as the basis for assuming that civilization is financially well-mixed and that wealth is derived most fundamentally from a capacity to enable a flow of potential energy from primary energy reserves. If it is generally correct, it enables an enormous simplification of what is required to accurately model the global economy and its waste products. At least at a global scale, a sophisticated IAM approach that explicitly considers people and their lifestyles is not necessary in order to forecast future rates of energy consumption. People do not need to be explicitly resolved in order to calculate global scale consumptive flows.

As a note, the constancy of $\lambda$ should not be expected to hold at national scales. One country could easily be relatively wealthy compared to its current rate of energy consumption, provided that other countries are relatively poor. The value of $\lambda$ is constant only as a global quantity, where $C$ and $a$ subsumes all countries that are connected through international trade. 


\section{Comparison with traditional economic growth models}

The model presented here is unlike traditional models in several regards, but it also has key similarities (see also Appendix B in Garrett, 2011). Wealth $C$ is analogous to the term "capital" used in traditional economic growth frameworks in the sense that it has units of currency, rather than currency per unit time. However, it is much more general. As shown in Fig. 1, civilization is defined as a whole, and no distinction is made between the human and non-human elements of the global economic system. Economic elements are not independent. Rather, all economic elements in civilization form a generalized capital that works in concert to consume primary energy reserves and enable the "downhill" flows of material in a field of potential energy.

Effectively, treating civilization as a whole means that it is assumed to be internally at local thermodynamic equilibrium, homogeneous, or "well-mixed". This does not mean that all economic elements are equal in value (they are not), only that the speed of financial interactions between all civilization elements is sufficiently rapid compared to the timescales of global economic growth that internal gradients can be ignored.

A consequence of treating civilization as a whole is that human labor is part of a more general expression of capital $C$. Traditional economic models separate "physical" capital from labor as distinct motive forces of economic production (Solow, 1956), sometimes including supplies of energy and raw materials in an appeal to thermodynamic constraints (Saunders, 2000; Warr and Ayres, 2006). Labor, capital and energy inputs are all set to exponents that are tuned to provide agreement with observed sectoral or national production statistics. Capital grows only due to "investments" that are separated from household and government "consumption". Household consumption never adds to capital. For one, people are not normally considered to be part of capital. For another, value that is consumed is presumed to be gone forever, so consumption must be subtracted from production to obtain the true capital investment.

Here, however, humans are subsumed into capital so that the production function, given by $P=\eta C$ (Eq. 9), is determined only by the general expression of capital used here and a variable rate of return $\eta$ that might be analogous to the "total factor productivity" employed by Solow (1956). Consequently, human consumption cannot be selectively subtracted from the production of new capital because humans are part of the whole. The component of economic production that is traditionally termed consumption is in fact an investment in sustaining and growing humanity.

That said, physically it makes most sense to refer to consumption as something that is much more extensive than what is directly tallied in economic accounts. In Fig. 1, consumption is proportional to the global scale flow of primary energy resources as it passes through civilization. This consumptive flow of matter and potential energy is downhill from high to low potential at right angles to the constant potential surface along which civilization lies. Economic production is proportional to the expansion of this potential surface. Thus, consumption and production cannot be differenced because the two quantities are mathematically orthogonal. Consumption is not a component of production, but rather production is the convergence in thermodynamic consumption. Only if civilization as a whole consumes more energy than it dissipates can the interface expand and net economic value be produced.

An added advantage of subsuming labor into capital, where capital is fundamentally assumed to be an implicit representation of energy consumption through $a \equiv \lambda C$, is that, unlike traditional models, there is no need for any tuning of non-integer exponents in a production function. Tuning to prior data can be a useful tool of last resort. But, it has its problems because there is little guarantee that a model tuned to the past will not need retuning to be consistent with data in the future. While the physical approach discussed here may be highly unorthodox by mainstream economic standards, it does have the advantage that its absence of a tuning requirement allows it to rest on a testable, falsifiable hypothesis falsifiability is one of the key hallmarks of science. Either there exists a constant coefficient $\lambda$, or there does not. Of course, as discussed above, the constancy in $\lambda$ does appear to hold. But the point is that if this constancy ever fails, then the model presented here can be safely dismissed. Retuning is not an option.

\section{Jevons' Paradox and why efficiency gains accelerate global $\mathrm{CO}_{2}$ emission rates}

Certainly, it might seem obvious that technological advances that increase energy efficiency or energy productivity (defined as $P / a$ ) should lead to a decrease in $\mathrm{CO}_{2}$ emissions. Less energy is required to accomplish the same economic task. Even so, there is recognition among many economists of the existence of a "rebound effect", whereby increasing energy productivity spurs greater emissions further down the road (Dimitropoulos, 2007; Herring and Roy, 2007; Sorrell, 2007). Two types of rebound have been identified, although in essence they both address the issue of what happens to whatever money is saved when energy productivity goes up. The "direct" rebound effect is limited to a particular energy service. For example, people may choose to drive more often if a vehicle is fuel efficient, because driving is useful or pleasurable and now more affordable. There are also "indirect rebound effects", which extend response to differing economic sectors. Less money spent on fuel for efficient vehicles might enable more money to be spent on fuel for home heating.

A few studies even point to an extreme form of rebound termed "backfire": gains in energy efficiency lead ultimately 
to more rather than less energy consumption (Saunders, 2000; Alcott, 2005; Owen, 2010; Alcott, 2010). First discussion of the principle came from an 1865 exposition on energy economics by William Stanley Jevons (Jevons, 1865). Jevons was emphatic that the introduction of energy efficient steam engines had accelerated Britain's consumption of coal. The cost of steam-powered coal extraction became cheaper and, because coal was very useful, more attractive.

While the topic has received revived attention politically (House of Lords, 2006), a general consensus on the total magnitude of the effect has proved elusive (Sorrell, 2007). One reason is that calculating the knock-on effects from an efficiency improvement in one sector as they propagate through the entire global economy is daunting if not impossible. Suppose that efficient vehicles enable added household heating through a savings in transportation costs. Then, by raising home comfort, workers sleep better so that they are better able to facilitate resource extraction at their companies. With higher profits, the companies then reward the workers with raises, who in turn spend the money on goods produced overseas with coal-generated electricity. So, in this fashion, the ramifications of any given efficiency action can multiply indefinitely, spreading at a variety of rates throughout the global economy. Barring global analysis of rebound effects over long time scales, conclusions may be quantitative but uncertain, and dependent on the time and spatial scales considered.

An easy way to address this problem is to not resolve economic flows within the global economy, but rather to take the more general approach shown in Fig. 1. In this case, energy efficiency is defined only with respect to the economic capacity of civilization, taken as a whole, to grow by doing work on its surroundings, allowing it to expand into the reserves of primary energy that sustain it. The amount of net or real work that civilization does to grow itself depends on a balance between civilization's consumptive and dissipative flows. If civilization is efficient, there is a net material and energetic convergence that allows civilization to do net positive work to "stretch" outward its interface with respect to its primary energy supplies. If energy efficiency increases, this accelerates civilization expansion, allowing civilization to consume energy at an ever faster rate.

Expressed in analytical terms, consumption of primary energy resources at rate $a$ enables work to be done at rate $w$ in order to extend the material size $\breve{n}$ of the interface that drives consumptive flows. From Eq. (1), work is done at rate

$w=\Delta \mu \frac{d \breve{n}}{d t}=\epsilon a$

where $\epsilon=w / a$ is the efficiency for the conversion of heat transfer to work. Unlike the normal conception, where work is done only to raise the potential of some outside agency, here work is more self-referential. Work is done by civilization to increase the size and consumptive capacity of civilization itself.
If net work is positive, then there is exponential growth in the rate of primary energy consumption $a$. Interface expansion into new energy reservoirs creates a positive feedback loop by bootstrapping civilization into an ever more consumptive state. Combining Eqs. (1) and (12), the rate of increase in energy consumption is related to the work done to expand the interface through

$\frac{d a}{d t}=\alpha \Delta \mu \frac{d \breve{n}}{d t}=\alpha w$

where, as before, $\alpha$ is an unknown constant. Since $w=\epsilon a$, dividing by $a$ provides an expression for the "rate of return" on consumption $\eta$, as defined previously in Eq. (8), that is directly proportional to energy efficiency through

$\eta=\frac{1}{a} \frac{d a}{d t}=\alpha \frac{w}{a}=\alpha \epsilon$.

Thus, global scale increases in the energy efficiency $\epsilon$ lead to a higher rate of return $\eta$ and accelerated growth of energy consumption rates $a$. Treated as a whole, an efficient system grows faster and consumes more.

That said, increasing energy efficiency does translate to higher prosperity. Economic production is related to the rate of return through $P=\eta C$ (Eq. 9), where wealth $C$ is tied to energy consumption through $a=\lambda C$ (Eq. 2), $\lambda$ being an empirically measurable constant. It follows that, at global scales, the energy productivity $P / a$ is tied to energy efficiency $\epsilon$ through

$\frac{P}{a}=\frac{\eta}{\lambda}=\frac{\alpha}{\lambda} \epsilon$.

The implication is that, at least for global economic systems, changes in energy efficiency and energy productivity are equivalent. Through Eq. (10), both accelerate GWP growth even if they do not in fact lead to a decrease in overall energy consumption, as is commonly assumed (Pacala and Socolow, 2004; Raupach et al., 2007). At global scales, Jevons' Paradox holds.

The analogy here might be to a growing child, who uses the material nutrients and potential energy in food not only to produce waste but also to grow. As the child grows, it eats more food, accelerating its growth until it reaches adulthood and growth stabilizes (in which case $\eta \simeq 0$ ). A healthy, energy efficient child will grow faster than one who is sick and inefficient. A diseased child may even die (in which case $\eta<0$ ).

These conclusions have direct bearing on global scale emissions of $\mathrm{CO}_{2}$. Just as civilization can be treated as being well-mixed over timescales relevant to economic growth, atmospheric concentrations of $\mathrm{CO}_{2}$ are also well-mixed over timescales relevant to global warming forecasts. Thus, for the purpose of relating the economy to atmospheric $\mathrm{CO}_{2}$ concentrations, what matters is only how fast civilization as a whole is emitting $\mathrm{CO}_{2}$. 
$\mathrm{CO}_{2}$ emissions are primarily a by-product of energy combustion. The emission rate $E$ is determined by the product of the global rate of energy consumption $a$, and the carbonization of the fuel supply defined by

$c \equiv \frac{E}{a}$

where, $E$ and $a$ are measured quantities. It follows from Eq. (2) that current rates of $\mathrm{CO}_{2}$ emissions $E$ are fundamentally coupled to wealth $C$, or past economic production, through

$E=\lambda c C=\lambda c \int_{0}^{t} P\left(t^{\prime}\right) d t^{\prime}$.

Drawing from statistics for $\mathrm{CO}_{2}$ emissions from the Carbon Dioxide Information Analysis Center (Marland et al., 2007), Table 1 shows that, like $a$ and $C, \mathrm{CO}_{2}$ emissions $E$ have approximately doubled between 1970 and 2008. Meanwhile, the value $\lambda c=E / C$ has stayed approximately constant. Its mean value (and uncertainty in the mean) taken from the entire yearly time series is $2.42 \pm 0.02$ ppmv atmospheric equivalent $\mathrm{CO}_{2}$ per year, per thousand trillion 1990 US dollars of global wealth.

Note that, unlike $\lambda$, the carbonization $c$ is not a fundamental property of the economic system within this framework. At least in principle, it could be more variable in the future than it has been in the recent past. Combining Eqs. (8) and (17), emission rates grow at rate that is determined by the growth rate of wealth and the rate of change of carbonization

$\frac{d \ln E}{d t}=\frac{d \ln C}{d t}+\frac{d \ln c}{d t}=\eta+\frac{d \ln c}{d t}$.

The implication is that, if technological changes allow energy productivity or energy efficiency to increase, then the rate of return $\eta$ increases and $\mathrm{CO}_{2}$ emissions accelerate. This is unless decarbonization is as rapid as the rate of growth of wealth $\eta$. If so, then emission rates $E$ can be stabilized. If, however, the carbonization $c$ stays approximately constant, then $\mathrm{CO}_{2}$ emissions rates $E$ will remain fundamentally linked to global economic wealth $C$ through the constant value of $2.42 \pm 0.02$ ppmv of $\mathrm{CO}_{2}$ emitted per year, per thousand trillion 1990 US dollars of current wealth. It can only be through an economic collapse that $\mathrm{CO}_{2}$ emissions rates will decline.

\section{Environmentally driven economic decay}

\subsection{Accounting of inflation and decay}

The broadest available measure of the inflation rate is the so-called GDP deflator, which is calculated from the yearon-year increase in the prices of a very broad basket of consumer and industrial goods. Effectively, the gross domestic product becomes devalued by some inflationary fraction $i$ that makes the "real", inflation-adjusted GDP less than its "nominal" value. Expressed for the world as a whole

$i=\frac{\text { nominal }- \text { real }}{\text { nominal }}=\frac{\mathrm{GWP}-\mathrm{GWP}}{\mathrm{GWP}}$.

While there have been a wide variety of theoretical explanations for what drives inflation, the field is fluid and none have been solidly rejected (Parkin, 2008). Price inflation is traditionally viewed as a simple imbalance between the monetary supply and economic output, and therefore mostly a matter for central bank control. What is less clear is why high inflation appears to have a negative effect on inflationadjusted economic growth (Sarel, 1996). There are also external forces that can create the initial inflationary pressure, such as an external shock to primary energy supplies (Bernanke et al., 1997), and even climate change, which drives up food prices through adverse effects on crop production (Lobell et al., 2011).

From the perspective of the model presented here, inflationary pressures can arise from either decreasing energy availability or increasing environmental disasters. This can be assessed because the real value or wealth of civilization is fixed to its current capacity to consume primary energy resources through the constant coefficient $\lambda$, which has a value of $9.7 \pm 0.3$ milliwatts per inflation adjusted 1990 dollar: in 2008, 16.4 TW of power supported 1656 trillion 1990 US dollars of civilization worth. For interpreting inflation, this coefficient provides an anchor for assessing real economic worth, at least for civilization as a whole.

Supposing that natural disasters destroy the capacity of life and property to consume energy, civilization's real value declines while plausibly keeping the availability of currency largely intact. Alternatively, while banks do not actively destroy civilization's capacity to consume energy, they might be excessively loose with currency. If so, the real currency value attached to the existing capacity to consume energy becomes diluted by an excessive availability of new currency, while real wealth stays fixed. Whether banks or climate extremes initiate the action, in either case, inflation should be expected to follow as a consequence of an introduced imbalance between real and nominal value. The availability of currency becomes out of proportion with the true capacity of civilization to consume primary energy supplies.

Real, inflation-adjusted wealth has been defined here by $C=\int_{0}^{t} P d t^{\prime}$ (Eq. 2) or equivalently, the instantaneous function $d C / d t \equiv P$ (Eq. 9), where $P$ is the inflation-adjusted production. Here, in effect, all production is a differential addition to a generalized measure of wealth, provided it is adjusted for inflation. This adjustment to the nominal (noninflation-adjusted) production of wealth $\hat{P}$ can be expressed as a sink of existing wealth $\gamma C$, where $\gamma$ represents the rate at which existing wealth is being destroyed or lost due to natural decay (Garrett, 2011)

$\frac{d C}{d t} \equiv P=\hat{P}-\gamma C$. 
Thus, the rate of decay is simply

$\gamma \equiv \frac{\hat{P}-P}{C}=\frac{\hat{P}-P}{\int_{0}^{t} P d t^{\prime}}$.

Similarly, the rate $\beta$ at which wealth $C$ leads to nominal production $\hat{P}$ can be defined by

$\beta \equiv \frac{\hat{P}}{C}=\frac{\hat{P}}{\int_{0}^{t} P d t^{\prime}}$.

In this case, from Eq. (20), the growth of wealth can be expressed as a balance between a source and a sink of wealth

$\frac{d C}{d t}=(\beta-\gamma) C$

This is just an alternative expression for Eq. (9) with the rate of return on wealth $\eta$ replaced by the difference between the coefficient of nominal production $\beta$ and the coefficient of decay $\gamma$

$\eta=\beta-\gamma$

The advantage of applying this treatment is that it leads to a very simple expression for an inflationary pressure $i$ in Eq. (19)

$i=\frac{\int_{t}^{t+\Delta t}(\hat{P}-P) d t^{\prime}}{\int_{t}^{t+\Delta t} \hat{P} d t^{\prime}}=\frac{\int_{t}^{t+\Delta t} \gamma C d t^{\prime}}{\int_{t}^{t+\Delta t} \beta C d t^{\prime}}=\frac{\langle\gamma\rangle}{\langle\beta\rangle}$

where brackets imply a mean over the time interval of calculation $\Delta t$, which is normally one year. Inflation is determined by the balance between the coefficients $\beta$ and $\gamma$ of production and decay. ${ }^{1}$ If $\Delta t$ is one year, then the quantity $i \Delta t$ represents the difference between nominal and real GWP.

If the coefficient of decay becomes greater than the coefficient of production, such that $\gamma>\beta$, then from Eq. (25), nominal production $\hat{P}$ may be positive, but real production $P$ is negative. Discussing negative real production would seem unusual (or impossible) from a traditional economic perspective that is geared towards modeling growth. From the more physical framework described here, it is simply a consequence of environmentally driven decay being so large that there are economic hyper-inflationary pressures associated

\footnotetext{
${ }^{1}$ In practice, statistics for nominal and real GWP are normally provided in current and fixed-year currency, respectively, and therefore are in different units. Thus, for a given time period $\Delta t$ (say one year), $\gamma$ can be calculated from differences in the logarithmic rate of expansion for $\hat{P}$ and $P$, noting that $\ln (1+x) \simeq x$

$\gamma=\frac{\hat{P}-P}{C} \simeq \frac{P}{C}\left[\frac{1}{P} \frac{d(\hat{P}-P)}{d t}\right] \Delta t \simeq \frac{P}{C} \frac{d \ln (\hat{P} / P)}{d t} \Delta t$.

Effectively $[d \ln (\hat{P} / P) / d t] \Delta t$ is the fractional inflation $i$ over period $\Delta t$. Then, since $\eta=P / C$, it follows that $\gamma=i \eta$ and $\beta=\eta+\gamma=(1+i) \eta$.
}

with a rate $i=\gamma / \beta$ that is greater than $100 \%$. Historically, and on more regional levels, this is in fact a fairly common scenario. From Eq. (20), $d C / d t<0$, and total wealth is in a state of collapse.

As discussed in Appendix A, hyper-inflation and collapse can be viewed thermodynamically as an interface between civilization and its energy reserves that is shrinking inwards rather than growing outwards. This means that the nominal work $\int_{t}^{t+\Delta t} \hat{w} d t^{\prime}$ that is done to grow civilization is overwhelmed by external work done on civilization through decay. Real or net work done to grow civilization $\int_{t}^{t+\Delta t} w d t^{\prime}$ turns negative and civilization enjoys no return on its energetic investment. As a whole, civilization becomes less wealthy as it becomes less able to consume primary energy reserves.

A related concept is termed Energy Returned on Energy Invested (or EROI), and is becoming increasingly popular as a metric of society's capacity to exploit primary energy reserves for economic benefit (Murphy and Hall, 2010). Evidence suggests that the value of EROI is declining, presumably as new energy reserves become increasingly difficult to access. In Appendix A it is shown that a direct link can be drawn between the EROI concept and inflation (or the GDP deflator) discussed here. At global scales, the value of EROI is equal to the inverse of the inflation rate.

\subsection{Inflationary pressures and civilization resilience}

The IPCC Working Group II (IPCC, 2007b) has identified potential societal damages due to climate "extremes", such as droughts and floods, and "means", such as sea-level rise. These will exert a negative feedback on civilization wealth such that, at some point, wealth and atmospheric $\mathrm{CO}_{2}$ become intrinsically coupled because civilization is no longer able to consume and emit as it has in the past.

Based on the above arguments, it is easy to see how natural disasters are often expected to be inflationary since they represent an increase in the work done by the environment on civilization. If the decay coefficient $\gamma$ suddenly rises, then from Eq. (20), this expands the difference between nominal and real production. From Eq. (25), the shock leads to inflation and less capacity to consume energy and emit $\mathrm{CO}_{2}$.

An important point here is that, for inflationary pressures to take hold, there must be an increase not just in total damages $\gamma C$, but in the coefficient of decay $\gamma$. Hurricane damages along the Atlantic seaboard have risen over the past century, but not because of a long-term increase in hurricane intensity or frequency (i.e. $\gamma$ ). Rather, economic wealth $C$ has become increasingly concentrated at the coasts (Pielke et al., 2008)

What seems reasonable is to expect that the decay rate $\gamma$ will in fact change over coming decades due to the increasingly harmful effects of global warming. Impacts will be regionally specific, but extremely difficult to predict. In light of this, the approach taken here is to simplify representation 


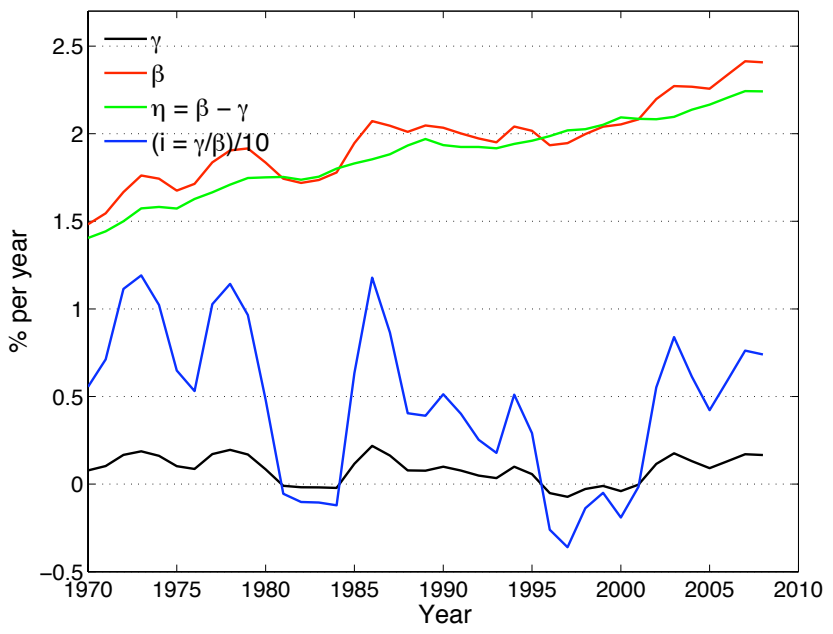

Fig. 2. From global economic statistics (United Nations, 2010), derived global values for global inflation $i$ (Eq. 25), the decay coefficient $\gamma$ (Eq. 21), the source coefficient $\beta$ (Eq. 22) and the rate of return $\eta$ (Eq. 24) based on observations of nominal and real production, and total global wealth.

of the global economic impacts of climate change by defining a global economic "resilience" to a logarithmic increase in atmospheric $\mathrm{CO}_{2}$ concentrations

$\rho=1 /\left(d \gamma / d \ln \left[\mathrm{CO}_{2}\right]\right)$.

If civilization's resilience is high, then the coefficient of decay $\gamma$ responds weakly to logarithmically changing $\mathrm{CO}_{2}$ levels. $^{2}$

There have been estimates of the regional societal and economic impacts from extremes in climate (Patz et al., 2005; Leckebusch et al., 2007; Hsiang et al., 2011). Unfortunately, it is not entirely obvious how to appropriately scale these impacts to civilization as a whole when many of the effects of climate change will be sustained, global, and largely unprecedented. Recent statistics do not yet provide meaningful guidance either. Figures 2 and 3 show no clear trends in the decay coefficient $\gamma$ that can easily be attributed to accelerating climate change. Up until this point, the dominant signature in $\gamma$ is only its inter-annual variability. A recent metaanalysis of disaster losses has arrived at a similar conclusion (Bouwer, 2011).

The hypothesis that is proposed here is that the effect on society of elevated levels of atmospheric $\mathrm{CO}_{2}$ will be akin to a prolonged natural disaster. From the standpoint of the economic model discussed above, the effect will be to steadily increase the coefficient of decay $\gamma$ without changing the coefficient of nominal production $\beta$. From Eq. (25), this will appear economically as an inflationary pressure that impedes

\footnotetext{
${ }^{2}$ The logarithm of $\mathrm{CO}_{2}$ concentrations is considered because the primary insulating gases responsible for climate warming, namely $\mathrm{CO}_{2}$ and water vapor, have a longwave absorptance that varies roughly as the square root of their concentrations (Liou, 2002).
}

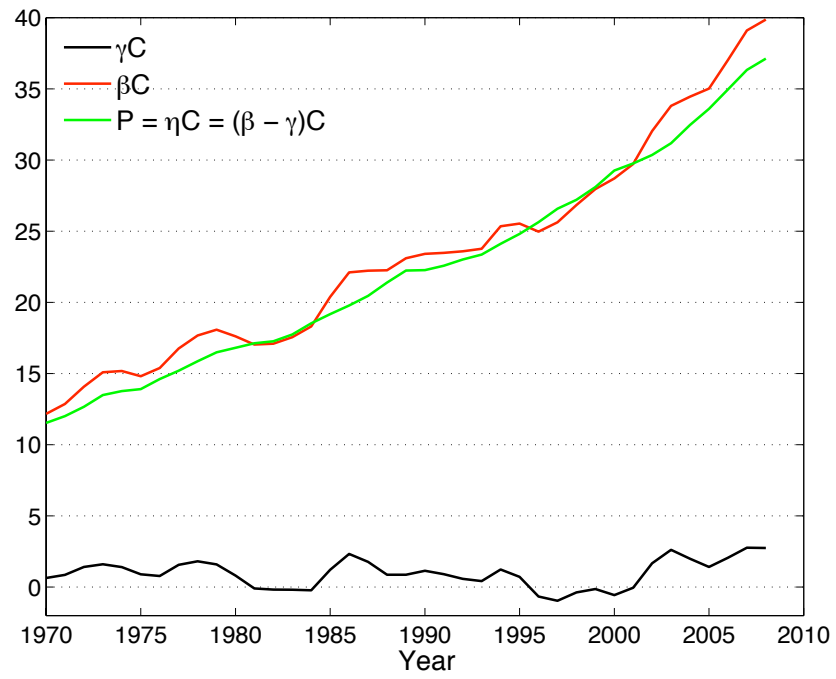

Fig. 3. As for Fig. 2 but for the product of the rate coefficients and total wealth $C$ (Eq. 4). The difference between $\beta C$ and $\eta C$ is the inflationary depreciation associated with each year $\gamma C$ (Eqs. 20 and 24).

the growth in wealth $C$, as described by Eq. (23). In a phase space of $\left[\mathrm{CO}_{2}\right]$ and $P$, the trajectory of civilization will depend on the resilience $\rho$ of civilization to elevated carbon dioxide levels: it is our resilience that will determine the strength of climate's negative feedback on economic growth.

\section{The Climate and Thermodynamics Economic Response Model (CThERM)}

To explore the coupling between civilization and the atmosphere, the following section introduces a very simple framework for forecasting the evolution of civilization in a phase space of $\left[\mathrm{CO}_{2}\right]$ and $P$, for a variety of assumed values of resilience $\rho$. The Climate and Thermodynamics Economic Response Model (CThERM) couples a prognostic economic model to atmospheric $\mathrm{CO}_{2}$ concentrations, as illustrated in Fig. 4. The prognostic economic module has just three coupled dynamic equations for wealth $C$, atmospheric $\mathrm{CO}_{2}$ concentrations $\left[\mathrm{CO}_{2}\right]$, and the rate of return $\eta$. From Eq. (8), wealth grows at rate

$\frac{d C}{d t}=\eta C$.

The balance between anthropogenic emissions $E=\lambda c C$ (Eq. 17) and natural sinks is

$\frac{d\left[\mathrm{CO}_{2}\right]}{d t}=E-\sigma \Delta\left[\mathrm{CO}_{2}\right]$

where $E=\lambda c C$ (Eq. 17) and $\sigma$ is an assumed linear sink rate on perturbations $\Delta\left[\mathrm{CO}_{2}\right]=\left[\mathrm{CO}_{2}\right]-\left[\mathrm{CO}_{2}\right]_{0}$ above some preindustrial baseline. For convenience, here it is assumed 


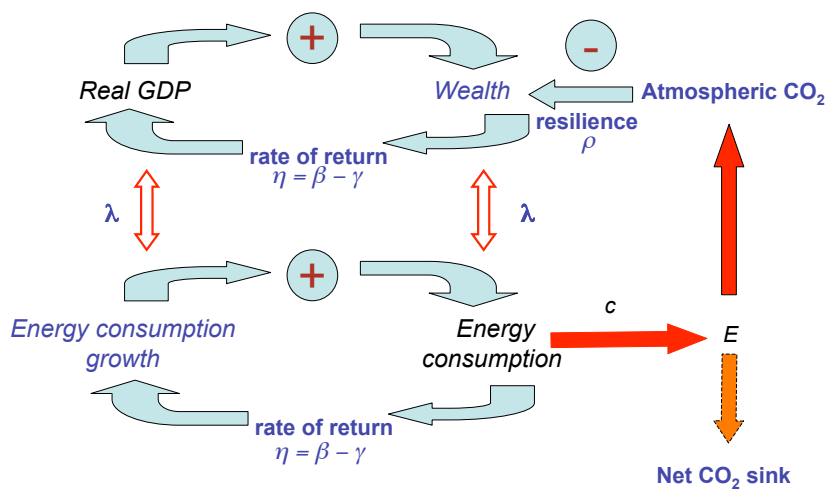

Fig. 4. Schematic illustrating the CThERM framework for economic growth (Garrett, 2011), coupled to atmospheric $\mathrm{CO}_{2}$ concentrations. Global rates of primary energy consumption rates $a$ are tied to accumulated inflation-adjusted global economic wealth $C=\int_{0}^{t} P d t^{\prime}$ through a constant coefficient $\lambda=9.7$ milliwatts per 1990 dollar. Because $\lambda$ is a constant, growth in energy consumption rates $d a / d t$ are represented economically by the real, inflationadjusted global GDP $P$. Thus, $d a / d t=\lambda P$ determines the "rate of return" $\eta=d \ln \eta / d t$ adding to $a=\lambda C$. $E$ represents the anthropogenic rate of $\mathrm{CO}_{2}$ emissions, $\beta$ is the source for a positive rate of return $\eta$ due to increasing availability of energy reservoirs. $\gamma$ is the sink for civilization growth driven by environmental degradation. Emissions $E$ determine $\mathrm{CO}_{2}$ concentrations, subject to land and ocean sinks. $\mathrm{CO}_{2}$ concentrations act as a negative feedback on economic growth.

that the $\mathrm{CO}_{2}$ emissions are instantly diluted in the total atmospheric mass (Trenberth, 1981) such that 1 ppmv atmospheric $\mathrm{CO}_{2}=2.13 \mathrm{Pg}$ emitted carbon. Thus $c$ is expressed in units of ppmv atmospheric $\mathrm{CO}_{2}$ emitted by civilization per Joule of energy consumption.

The modeling approach here is aimed at the simplest of possible approaches. In reality, the carbon cycle is much more complicated than can be easily justified by a linear sink model (Cox et al., 2000; Canadell et al., 2007). That said, even the current magnitude of the $\mathrm{CO}_{2}$ sink is not well constrained (Le Quéré et al., 2003). Given current uncertainties, assuming a linear sink that is in line with current observations appears to provide long-range forecasts of $\left[\mathrm{CO}_{2}\right]$ that are in good agreement with far more sophisticated models. More detailed discussion is presented in Sect. 7.3 and Appendix C.

From Eqs. (24) and (26), the rate of return $\eta$ changes at a rate given by

$\frac{d \eta}{d t}=\frac{d \beta}{d t}-\frac{1}{\rho} \frac{d \ln \left[\mathrm{CO}_{2}\right]}{d t}$.

Model trajectories in wealth $C$ and atmospheric carbon dioxide concentration evolve subject to initial conditions in $\left[\mathrm{CO}_{2}\right], C, \beta$ and $\gamma$. Note that global production $P$ is a diagnostic quantity given by Eq. (9).

The prognostic CThERM model expressed by Eqs. (27) to (29) is incomplete because it lacks prognostic equations for the carbonization of the world's wealth $c=E /(\lambda C)$

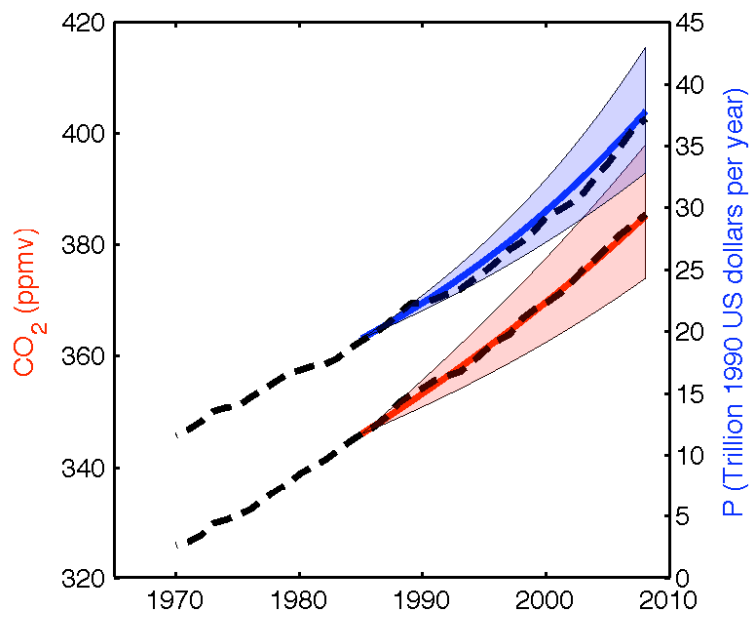

Fig. 5. Based on the CThERM model given by Eqs. (27) to (29), hindcast trajectories and associated uncertainty estimates for the period 1985 to 2008 in a space of atmospheric $\mathrm{CO}_{2}$ concentrations (red) and global economic production (blue). Observed statistics for the period 1970 to 2008 are shown by black dashed lines. The model is initialized with observed conditions in 1985, and a linear trend in the nominal production coefficient $\beta$ between 1970 and 1984.

(Eq. 17) and the coefficient of nominal production $\beta=\hat{P} / C$ (Eq. 22). A more sophisticated model will need to address the evolution of these terms. ${ }^{3}$

A hindcast simulation that illustrates the accuracy of the model framework is shown in Fig. 5. The hindcast is initialized in 1985 and, based on results shown in Fig. 2, it is assumed that $d \gamma / d t=0$ and that $d \beta / d t$ evolves on a linear trajectory that is consistent with what is observed for the period between 1970 and 1984. A linear fit for $d \beta / d t$ during this initialization time period is $0.017 \% \mathrm{yr}^{-1}$ per year with a $95 \%$ confidence limit of $\pm 0.01 \% \mathrm{yr}^{-1}$ per year. A second source of uncertainty is associated with the $\mathrm{CO}_{2}$ sink coefficient $\sigma$, which is estimated to have a value of $1.55 \pm 0.75 \% \mathrm{yr}^{-1}$ (Appendix B).

Figure 5 shows that, with these assumptions, the midrange of hindcasts over a 23 year period between 1985 and 2008 faithfully reproduces both the timing and magnitude of observed changes in atmospheric $\mathrm{CO}_{2}$ concentrations and global economic production $P$. The implication is that, even though the model that is used is extremely simple, it is nonetheless able to make accurate multi-decadal forecasts for

\footnotetext{
${ }^{3}$ In principle, the evolution of $\beta$ is governed by two factors, as illustrated in Fig. 1. As civilization or any other system grows, it depletes known available energy reservoirs; at the same time, it expands into new reservoirs that were previously unavailable or unknown. Past bursts in growth in $\eta=\beta-\gamma$ are seen to have occurred around 1880 and 1950, perhaps due to a sudden increase in availability of important new oil reservoirs (Garrett, 2011). Presumably the future availability of energy reservoirs will influence the value of $c$ as well (Sorrell et al., 2010).
} 


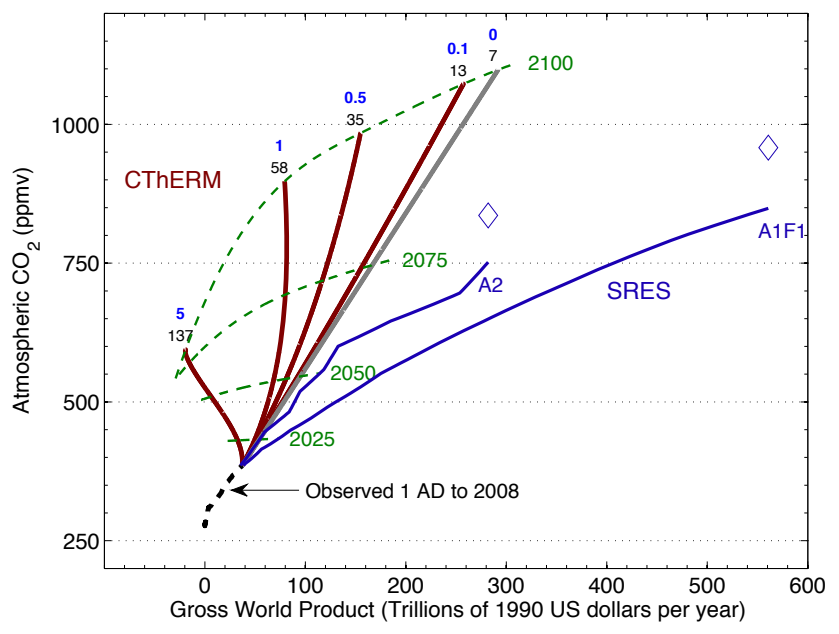

Fig. 6. As for Fig. 5, except for CThERM trajectories calculated out to 2100, with the model initialized with conditions in 2008 and assuming that $d \beta / d t=0$ and $d c / d t=0$ for a range of values of inverse resilience $1 / \rho$ (blue numbers expressed in $\% \mathrm{yr}^{-1}$ change in the decay coefficient $\gamma$ per $\mathrm{CO}_{2}$ doubling). Small numbers in black correspond to the calculated inflationary pressure $i=\gamma / \beta$ (Eq. 25) in year 2100. Green dashed lines represent the modeled year. Shown for comparison are the IPCC SRES A1F1 and A2 scenarios based on the CThERM linear sink model for $\mathrm{CO}_{2} \cdot \mathrm{CO}_{2}$ concentrations for these scenarios using the Bern carbon cycle model are shown by blue diamonds. Historical data from $1 \mathrm{AD}$ to 2008 is added for reference (see Appendix C).

the coupled growth of the global economy and atmospheric composition. Furthermore, it suggests some ability of the model to explore thermodynamically constrained forecasts in a space of $P$ and $\left[\mathrm{CO}_{2}\right]$ for a range of hypothetical values of civiilization resilience $\rho$ and decarbonization rates $-d \ln c / d t$.

As discussed previously, there is no good guidance yet for what a suitable choice for the resilience $\rho$ might be, and no prognostic model is included here for forecasting the evolution of either carbonization $c$ or the nominal productivity coefficient $\beta$. Thus, while the CThERM model is thermodynamically constrained, it can still only provide forecasts for a range of hypothetical scenarios in these parameters. In what follows, two main categories of scenarios are considered.

\subsection{Forecast scenario A: no decarbonization}

The first scenario that is considered here is simply to assume that for the remainder of this century, there will be no further decarbonization, and that the coefficient of nominal production will remain stagnant (i.e. $d c / d t=0$ and $d \beta / d t=0$ ). Figure 6 shows examples of forecasts for these conditions for the years between 2009 and 2100. Also shown for historical reference are past measurements between $1 \mathrm{AD}$ and 2008 (Appendix C).

For this scenario, a range of resilience sub-scenarios can be considered. If civilization is so resilient that it is unaffected by elevated $\mathrm{CO}_{2}$ levels, then the world economy $P$ sustains recent growth rates of $2.2 \%$ per year. By 2100 , it increases by nearly an order of magnitude to a value of nearly 300 trillion 1990 dollars per year. The accumulated production of wealth $C \equiv \int_{0}^{2100} P d t^{\prime}$ corresponds to an increase in rates of energy consumption $a=\lambda C$ from $16 \mathrm{TW}$ in 2008 to $126 \mathrm{TW}$ in year 2100 . Absent any decarbonization, the accumulated and accelerating emissions push $\mathrm{CO}_{2}$ levels above 1100 ppmv.

If, however, civilization has an extremely low resilience to elevated $\mathrm{CO}_{2}$ levels, then the decay coefficient $\gamma$ increases by $5 \% \mathrm{yr}^{-1}$ per $\mathrm{CO}_{2}$ doubling. Eventually, the decay coefficient exceeds the coefficient of nominal production $\beta$. In this case, economic production shrinks due to the impacts of climate change. Well before the year 2100 , the inflationary pressure exceeds $100 \%$ : real GDP is negative and civilization is in a phase of collapse. However, even in this scenario, energy consumption rates peak at $89 \mathrm{TW}$ in 2056 and although they fall to 21 TW in year 2100, they still exceed current levels. Because rates of energy consumption remain high, even with rapid and immediate civilization collapse, $\mathrm{CO}_{2}$ levels still continue their rise to approximately $600 \mathrm{ppmv}$ by year 2100.

What is perhaps most striking when looking at these forecasts is that we can expect some extraordinarily rapid nearterm changes in the global economy and atmospheric composition. For any plausible resilience condition, atmospheric $\mathrm{CO}_{2}$ concentrations and civilization GWP will change by as much in the next 40 years as they have in the past two thousand.

\subsection{Forecast scenario B: rapid decarbonization}

Although there is no evidence that civilization is in fact decarbonizing (Raupach et al., 2007), one can imagine for the sake of illustration a second forecast scenario shown in Fig. 7 in which $\beta$ stays constant, but the carbonization of civilization $c$ drops extremely rapidly. Supposing that carbonization $c$ halves in just 50 years, the value of $c$ ends up $73 \%$ lower in 2100 than it is at present. This is highly imaginary, of course. If nothing else, no consideration is made here of the costs of decarbonizing that would be involved. These would presumably act to lower $\beta$ and be an inflationary pressure themselves (Eq. 25). However, it is worth considering because, for one, it illustrates how extremely rapid decarbonization would need to be to lower $\mathrm{CO}_{2}$ concentrations to something that only moderately exceeds the $450 \mathrm{ppmv}$ levels that might be considered to be "dangerous" (Hansen et al., 2007). If civilization's resilience to climate change is extremely low, then only a combination of rapid civilization collapse and high decarbonization comes close to achieving a $450 \mathrm{ppmv}$ goal. Otherwise, if civilization's resilience to climate change is extremely high, then emissions increase from $3.95 \mathrm{ppmv}$ equivalent per year in 2008 to 8.64 ppmv per year in 2100 . 


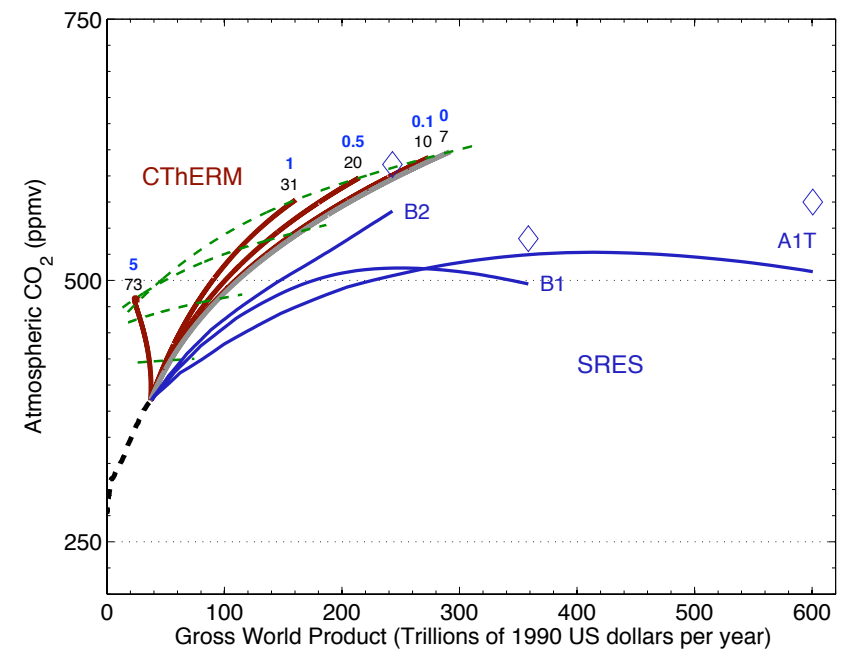

Fig. 7. As for Fig. 6 except that it is assumed that the value of carbonization $c$ has an assumed halving time of 50 years. For comparison, the IPCC SRES trajectories that are considered are the A1T, $\mathrm{B} 1$ and $\mathrm{B} 2$ scenarios.

The reason why even rapid decarbonization still corresponds with increasing emissions rates is that it has the side benefit of aiding economic health and growth. By slowing growth in $\mathrm{CO}_{2}$ concentrations, the worst impacts of future climate change are constrained. Energy consumption is fundamentally linked to the size of civilization through the constant $\lambda$ (Eq. 11). Thus, any improvement to economic wealth corresponds to increased energy consumption and more rapid growth in $\mathrm{CO}_{2}$ emissions (Eq. 18).

It is counter-intuitive, but comparing two scenarios with very low resilience to climate change, energy consumption rates rise about twice as fast with rapid decarbonization as with no decarbonization. The reason is that decarbonization aids society health by limiting global warming. Better health means greater energy consumption, which then leads to a partial offset of any environmental gains that came from decarbonizing in the first place.

\subsection{Comparison with SRES scenarios}

Figures 6 and 7 include for comparison's sake the phase space of $P$ and $\mathrm{CO}_{2}$ concentrations that are employed in several well-known IPCC Special Report on Emissions Scenarios (SRES) illustrative marker scenarios (IPCC, 2007a; Manning et al., 2010). These scenarios provide statistics through 2100 for global GWP in 1990 MER US dollars along with global $\mathrm{CO}_{2}$ emission rates from fossil fuel combustion. For the sake of consistency with CThERM calculations, atmospheric $\mathrm{CO}_{2}$ concentrations are calculated from the second CThERM equation given by Eq. (28). Across the scenarios, calculated trajectories in $\mathrm{CO}_{2}$ concentration perturbations are lower than those presented in the IPCC Third Report for the same emission rates, but calculated using the sophisticated
"Bern" carbon cycle model (Joos et al., 1996). Part of this discrepancy may be because no consideration is made for the small additional perturbations in anthropogenic $\mathrm{CO}_{2}$ emissions that come from future non-fossil fuel sources. But also, no account is made for possible future saturation of $\mathrm{CO}_{2}$ sinks (Le Quéré et al., 2007). Regardless, the agreement is still sufficiently favorable to support using the extremely simple $\mathrm{CO}_{2}$ sink model in Eq. (28) as an accessible, if conservative, substitute for the more sophisticated approaches used by the IPCC.

The comparisons between the CThERM and SRES scenarios are grouped according to whether or not decarbonization is included in the forecasts. CThERM trajectories in Fig. 6 include no decarbonization, and are paired with the A1F1 and A2 scenarios. These two SRES storylines are both based on a fossil-fuel reliant economy, while A1F1 has faster economic growth. For contrast, the CTheRM trajectories in Fig. 7 do include decarbonization, and are paired with the A1T, B1 and B2 scenarios. These storylines all include a switch to less carbon intensive fuels, but with a range of speeds of economic development.

Regardless of the precise scenario that is considered, there is a basic difference between the CThERM forecasts and the SRES scenarios. Each SRES scenario greatly underestimates how much atmospheric $\mathrm{CO}_{2}$ concentrations will rise for a given level of global GWP. Or, put another way, SRES scenarios produce an unphysical overestimate of the wealth society can have while maintaining $\mathrm{CO}_{2}$ levels below some nominal threshold. For example, the "environmentally sustainable" $\mathrm{B} 1$ scenario suggests that a $\mathrm{CO}_{2}$ level below 500 ppmv is plausible by the end of this century, while maintaining a GWP of 360 Trillion 1990 US dollars per year. The CThERM results suggest that this combination simply cannot happen because, even with rapid decarbonization, sustaining this level of economic activity would require too much energy consumption. It is only with rapid decarbonization and civilization collapse that such $\mathrm{CO}_{2}$ concentrations can be attained.

Perhaps the basic reason that there is a mismatch between the CThERM and SRES scenarios is that the SRES scenarios are based on an assumption that increases in energy efficiency will lower the amount of $\mathrm{CO}_{2}$ emitted for a given amount of economic activity. The thermodynamic and observational analyses described here and in Garrett (2011) indicate that the opposite should be expected to hold. From Eq. (14), gains in efficiency $\epsilon$ accelerate $\mathrm{CO}_{2}$ emissions by accelerating civilization's capacity to access primary energy reservoirs. While, increasing efficiency may also lead to a higher GWP (Eq. 15), feedbacks in the economic system make it impossible to decouple the energy consumption from economic well-being. 


\section{Conclusions}

This study builds on a key result presented in a prior article (Garrett, 2011), that civilization wealth and global rates of primary energy consumption are tied through a constant value of $\lambda=9.7 \pm 0.3 \mathrm{~mW}$ per 1990 US dollar. On this basis, a very simple prognostic model (CThERM) is introduced for forecasting the coupled evolution of the economy and atmospheric $\mathrm{CO}_{2}$ concentrations. While the model in its basic form has just three prognostic equations, it nonetheless provides accurate multi-decadal hindcasts for global world production and atmospheric concentrations of $\mathrm{CO}_{2}$.

The much more sophisticated formulations commonly used in Integrated Assessment Models can have hundreds of equations. In part this is required to forecast regional variations of specific societal indicators such as population or standard of living. The argument made here and in Garrett (2011) is that, at the global scales relevant to atmospheric composition, such complexity is largely unnecessary. Both the global economy and atmospheric $\mathrm{CO}_{2}$ can be considered to be "well-mixed", and they both are constrained by the global rate of primary energy consumption.

One implication of this result is that global warming should be expected to manifest itself economically as a growing gap between the nominal and inflation-adjusted GWP. Environmental pressures erode a material interface that enables civilization to consume the primary energy resources it requires. Normally, this erosion is more than offset by increasing access to primary energy reservoirs; in fact, it is an increasing access to energy supplies that has enabled a positive (and growing) inflation-adjusted gross world product, and has led to the generally high standard of living we enjoy today. However, in a global warming scenario, it can be expected that environmental pressures will increase, and these will act to slow growth in energy consumption. Fiscally, this will appear as an inflationary drag on the growth of economic wealth. Ultimately, it is conceivable that it will push civilization towards an accelerating decline.

Another implication is that the commonly used IPCC SRES scenarios make unphysical underestimates of how much energy will be needed to be consumed, and $\mathrm{CO}_{2}$ emitted, to sustain prosperity growth. At the globally relevant scales, energy efficiency gains accelerate rather than reduce energy consumption gains. They do this by promoting civilization health and its economic capacity to expand into the energy reserves that sustain it.

Reductions in $\mathrm{CO}_{2}$ emissions can be achieved by decarbonizing civilization's sources of fuel. But this has an important caveat. Decarbonization does not slow $\mathrm{CO}_{2}$ accumulation by as much as might be anticipated because it also alleviates the potential rise in atmospheric $\mathrm{CO}_{2}$ concentrations. If decarbonization leads to fewer climate extremes, then economic wealth is supported; and, because wealth is tied to energy consumption through a constant, improving wealth partly offsets the anticipated $\mathrm{CO}_{2}$ emission reductions. Ultimately, civilization appears to be in a doublebind with no obvious way out. Only a combination of extremely rapid decarbonization and civilization collapse will enable $\mathrm{CO}_{2}$ concentrations to be stabilized below the 450 ppmv level that might be considered as "dangerous" (Hansen et al., 2007).

\section{Appendix A}

\section{Thermodynamic accounting of decay}

The fiscal arguments for inflation discussed in Sect. 6.1 can be represented within the context of the generalized thermodynamic framework illustrated in Fig. 1. Global wealth can be related to thermodynamic flows through the constant $\lambda$, as framed by Eq. (11) and validated through observations (Table 1). From Eq. (12), thermodynamic work $w$ can be defined as the net growth rate in an interface with potential difference $\Delta G$ and number of material units $\breve{n}$. The interface drives downhill thermodynamic flows at rate $a=\alpha \Delta G=\breve{n} \Delta \mu$, where $\Delta \mu$ is a fixed potential jump per unit matter.

Thus, from Eq. (8), thermodynamic work is done by civilization to expand the interface at rate

$w=\frac{d \Delta G}{d t}=\Delta \mu \frac{d \breve{n}}{d t}$.

Equation (8) dictates that, since $\lambda$ is a constant, the rate of return $\eta$ applies equally to thermodynamic flows $a$, the size of the potential difference at the interface that drives flows $\Delta G$, and wealth $C$. It follows that the thermodynamic analog for the economic growth equations given by Eqs. (20) or (23) is

$\frac{d \Delta G}{d t}=\eta \Delta G=\hat{w}-\gamma \Delta G=(\beta-\gamma) \Delta G$.

What this expresses is the details of how the interface shown in Fig. 1 grows. Civilization grows by doing "nominal" work to stretch the interface driving flows outward at rate $\hat{w}=\beta \Delta G$. By extension of Eq. (6), nominal work is the thermodynamic expression of nominal economic production through

$\hat{P}=\frac{\alpha \hat{w}}{\lambda}=\frac{\alpha}{\lambda} \beta \Delta G$.

However, it is only the "real" portion of work $w=d \Delta G / d t$ that contributes to the net or real rate of interface growth: for real growth to occur, nominal work $\beta \Delta G$ must be sufficiently rapid to overcome natural decay $\gamma \Delta G$. Thus, real production $P$ is related the size of the interface $\Delta G$ through

$P=\frac{\alpha w}{\lambda}=\frac{\alpha}{\lambda}(\beta-\gamma) \Delta G$.

Expressed in this fashion, real economic production is a balance between two opposing thermodynamic forces shown in Fig. 1. There is an interface that connects civilization to 
available energy reservoirs. Flow across this interface arises from a consumption of primary energy resources. By consuming energy, civilization both sustains its current size and does nominal work to "stretch" outward the size of the interface at rate $\beta$. As the interface grows, it makes previously innaccessible or unknown reservoirs of high potential energy (such as oil, coal, uranium, etc.) newly available. It is by consuming and doing work that consumption accelerates.

However, this stretching only drives "nominal" growth. "Real" growth takes into account environmental pressures that erode the interface at rate $\gamma$. Such "predation" of civilization by the environment is due to a loss of matter as things fall apart. There are many forms of material loss. Photons are radiated through thermal heat loss; mass falls down due to gravitation, and electrons are redistributed due to chemical reactions. What matters from civilization's perspective is that this constant loss of material hinders gains from nominal work $\hat{w}$. This slows the growth of the interface $\Delta G=\Delta \mu \breve{n}$ that drives flows, and consequently it dampens growth in energy consumption $a$ and wealth $C$. Due to material loss, only net or real work is done at rate $w$.

Thus, from Eqs. (A3) and (A4), the thermodynamic form of the expression for economic inflation given by Eq. (25) is

$$
\begin{aligned}
i & =\frac{\int_{t}^{t+\Delta t}(\hat{P}-P) d t^{\prime}}{\int_{t}^{t+\Delta t} \hat{P} d t^{\prime}}=\frac{\int_{t}^{t+\Delta t}(\hat{w}-w) d t^{\prime}}{\int_{t}^{t+\Delta t} \hat{w} d t^{\prime}} \\
& =\frac{\int_{t}^{t+\Delta t} \gamma \Delta G d t^{\prime}}{\int_{t}^{t+\Delta t} \beta \Delta G d t^{\prime}}=\frac{\langle\gamma\rangle}{\langle\beta\rangle} .
\end{aligned}
$$

As a note, a direct link can be drawn here to the increasingly popular concept of Energy Returned on Energy Invested (EROI) (Murphy and Hall, 2010). The dimensionless EROI factor expresses how much energy society is able to recoup for consumption, relative to the amount of energy it must expend to access the energy. A point that is sometimes made is that the EROI is declining as new oil reserves become increasingly difficult to discover.

Here, the real rate of doing work $w$ is defined as the expansion in the potential gradient $\Delta G$, where the potential drives the flows of energy to society at rate $a$. Real work expands energy consumption at rate $d a / d t=\alpha w=\alpha d \Delta G / d t$ (Eq. 13). From Eq. (A2), civilization expansion is positive if there is a convergence of flows and the amount of potential energy that must be "expended" in an effort to grow civilization energy consumption $\int_{t}^{t+\Delta t} \alpha \gamma \Delta G d t^{\prime}$ is less than the increase in the amount of potential energy that becomes newly available to be "consumed" $\int_{t}^{t+\Delta t} \alpha \beta \Delta G d t^{\prime}$. Thus, the EROI concept is expressible thermodynamically as

$$
\begin{aligned}
\text { EROI } & =\frac{\text { Energy Consumption Gain }}{\text { Energy Expenditure }}=\frac{\int_{t}^{t+\Delta t} \hat{w} d t^{\prime}}{\int_{t}^{t+\Delta t}(\hat{w}-w) d t^{\prime}} \\
& =\frac{\int_{t}^{t+\Delta t} \alpha \beta \Delta G d t^{\prime}}{\int_{t}^{t+\Delta t} \alpha \gamma \Delta G d t^{\prime}}=\frac{\langle\beta\rangle}{\langle\gamma\rangle}
\end{aligned}
$$

Since this is just the inverse of Eq. (A5), the EROI is inversely tied to inflationary pressures through

$i=\frac{1}{\text { EROI }}$.

For example, a global EROI of 20 calculated over a given time period $\Delta t$, corresponds to a corresponding inflationary pressure of $5 \%$. If global civilization ever gets to the point that it expends as much energy during the extraction process as it is able to consume in return, then the inflationary pressure is $100 \%$, the EROI value is unity and civilization wealth $C$ is on the verge of tipping into collapse. Any expansion work that civilization does serves only to maintain a standstill.

\section{Appendix B}

\section{Parameterization of a linear sink term for $\mathrm{CO}_{2}$}

A portion of the anthropogenic $\mathrm{CO}_{2}$ that is accumulating in the atmosphere has a concurrent sink to the land and oceans, both from natural processes and changes associated with land-use. The nature of the sink is complex, and depends on multiple processes with timescales that vary by orders of magnitude. Detailed assessments of the magnitude, trends, and uncertainties in the airborne fraction of $\mathrm{CO}_{2}$ emissions $E$ are provided by Canadell et al. (2007), and ideally would require a fully coupled earth system model.

For the sake of simplicity of argument, the carbon dioxide sink is assumed here to be a linear function of the disequilibrium in atmospheric $\mathrm{CO}_{2}$ concentrations $C$. To see why this might not be as terrible a choice as it might initially appear, consider the simple analytic representation of a detailed carbon cycle model (Joos et al., 1996), which shows that a small pulse of $\mathrm{CO}_{2}$ into the atmosphere decays over multiple timescales (Hansen et al., 2007):

$$
\mathrm{CO}_{2}(\%)=18+14 e^{-t / 420}+18 e^{-t / 70}+24 e^{-t / 21}+26 e^{-t / 3.4} .
$$

This formulation points to multiple sink coefficients with decay weighted towards shorter timescales, meaning that recent, faster emissions decay at a more rapid rate than older, slower contributions. Thus, super-exponential (i.e. the exponent of an exponent) emissions growth would progressively bias the instantaneous, or effective, value of the sink rate to ever shorter timescales. If, however, $\mathrm{CO}_{2}$ emissions grow nearly at a logarithmically constant rate, then the linear sink rate for these $\mathrm{CO}_{2}$ emissions $\sigma$ (Eq. 28) should be approximately constant with time.

Currently, $\mathrm{CO}_{2}$ emissions growth is nearly exponential, so assuming that $\sigma$ is nearly constant, its value can be estimated by combining data for the ocean and land sink (Le Quéré et al., 2003) with an assumed pre-industrial equilibirum concentration of $275 \mathrm{ppmv}$ (Wigley, 1983). This leads to an approximate value for $\sigma$ of $1.55 \pm 0.75 \%$ per annum, corresponding to a sink timescale of about 65 years (Table B1). 
Table B1. Estimates of the annual ocean and land net sink for carbon (in $\mathrm{PgC} \mathrm{yr}^{-1}$ ), including those associated with land-use changes (Le Quéré et al., 2003), the total sink (in ppmv $\mathrm{CO}_{2} \mathrm{yr}^{-1}$ ), the decadal mean value of the carbon dioxide disequilibrium above $275 \mathrm{ppmv}\left[\Delta \mathrm{CO}_{2}\right]$, and the associated linear sink coefficient $\sigma$ $\left(\% \mathrm{yr}^{-1}\right)$. For convenience, the total sink is expressed in units of ppmv atmospheric $\mathrm{CO}_{2}$ per year through division by the total atmospheric mass (Trenberth, 1981), such that $1 \mathrm{ppmv} \mathrm{CO}_{2}=2.13 \mathrm{Pg}$ emitted carbon.

\begin{tabular}{rrrrrr}
\hline & Ocean sink & Land sink & $\begin{array}{r}\text { Total sink } \\
\text { (in ppmv } \\
\left.\mathrm{CO}_{2} \mathrm{yr}^{-1}\right)\end{array}$ & {$\left[\Delta \mathrm{CO}_{2}\right]$} & $\begin{array}{c}\sigma \\
\left(\% \mathrm{yr}^{-1}\right)\end{array}$ \\
\hline $1980 \mathrm{~s}$ & $1.8 \pm 0.8$ & $0.3 \pm 0.9$ & $1 \pm 0.6$ & 70 & $1.4 \pm 0.9$ \\
$1990 \mathrm{~s}$ & $1.9 \pm 0.7$ & $1.2 \pm 0.8$ & $1.5 \pm 0.5$ & 85 & $1.7 \pm 0.6$ \\
\hline
\end{tabular}

The above framework neglects changes in $\mathrm{CO}_{2}$ sinks that might be expected to change in the future if, for example, there is saturation of the ability of the earth's ecosystems and oceans to uptake carbon (Cox et al., 2000; Le Quéré et al., 2007). Certainly the systems involved are complex and this adds to the difficultly of making confident quantification of future behavior. Simply estimating a constant linear sink coefficient for atmospheric $\mathrm{CO}_{2}$ based on recent observations is aimed more at simplicity than accuracy, and certainly more sophisticated forecasts than presented here could implement some functional dependence for $\sigma\left(\left[\Delta \mathrm{CO}_{2}\right]\right)$. However, given that there are such large uncertainties on even the current magnitude of the $\mathrm{CO}_{2}$ sink, assuming a linear sink coefficient seems adequate until estimates of carbon fluxes can be further constrained.

\section{Appendix C}

\section{Historical records of economic production and $\mathrm{CO}_{2}$ concentrations}

Historical measurements of atmospheric $\mathrm{CO}_{2}$ perturbations from an assumed baseline of 275 ppmv are shown in Fig. C1. Measurements come from a combination of in-situ measurements from Mauna Loa (Keeling and Whorf, 2005), and Antarctic ice core data from the EPICA Dome C (Flückiger et al., 2002) and the Law Dome (Etheridge et al., 1996). These data are compared to a time series for measurements of global world production that is derived from a combination of statistics in 1990 market exchange rate dollars available since 1970 (United Nations, 2010) and more intermittent, long-term historical estimates for the years 0 to 1992 derived by Maddison (2003). For details see Garrett (2011). Although it is unclear exactly why, the two millennia data in production $P$ and and $\left[\Delta \mathrm{CO}_{2}\right]$ are well-represented by a remarkably simple power-law fit that accounts for $90 \%$ of the variance $(r=0.952)$

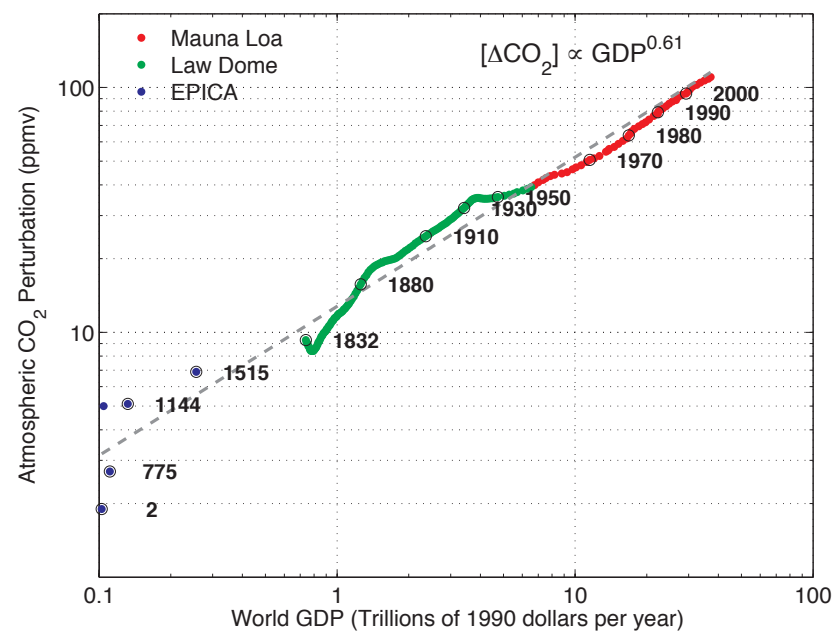

Fig. C1. Measured perturbations in atmospheric $\mathrm{CO}_{2}$ concentrations from a baseline of 275 ppmv, compared with historical estimates of global GDP in inflation adjusted 1990 dollars, with associated year markers, and a linear fit to the data.

$\left[\Delta \mathrm{CO}_{2}\right]=2.5 P^{0.61}$.

The results suggest a fairly long term anthropogenic influence on atmospheric composition. It might be tempting to infer from these data that $\mathrm{CO}_{2}$ measurements at Mauna Loa could be used to gauge the size of the global economy. However, obviously the observed relationship between $\left[\Delta \mathrm{CO}_{2}\right]$ and $P$ must break down sometime in the future. $P$ is an instantaneous quantity, whereas $\mathrm{CO}_{2}$ perturbations decay over timescales of hundreds to thousands of years (Eq. B1).

Acknowledgements. Writing of this article benefited from a helpful review by Carsten Hermann-Pillath, discussions about Economics with Steve Bannister, Harry Saunders, Clint Schmidt, Todd Kiefer, and Richard Fowles, and Earth System Models with Court Strong. This research was funded in part by the Ewing Marion Kauffman Foundation whose views it does not represent.

Edited by: A. Kleidon

\section{References}

AER - Annual Energy Review 2009: Tech. Rep. DOE/EIA0384(2009), Department of Energy, Energy Information Administration, www.eia.doe.gov/aer/inter.html (last accessL: December 2010), 2009.

Alcott, A.: Impact caps: why population, affluence and technology strategies should be abandoned, J. Clean. Prod., 18, 552-560, 2010.

Alcott, B.: Jevons' paradox, Ecol. Econ., 54, 9-21, 2005.

Allan, R. P. and Soden, B. J.: Atmospheric Warming and the Amplification of Precipitation Extremes, Science, 321, 1481-1484, 2008. 
Annila, A. and Salthe, S.: Economies Evolve by Energy Dispersal, Entropy, 11, 606-633, 2009.

Ayres, R. U., Ayres, L. W., and Warr, B.: Exergy, power and work in the US economy, 1900-1998, Energy, 28, 219-273, 2003.

Bernanke, B. S., Gertler, M., Watson, M. C. S., and Friedman, B. M.: Monetary policy and the effects of oil price shocks, Brookings Papers on Econonomic Activity, 1, 91-157, 1997.

Bouwer, L. M.: Have Disaster Losses Increased Due to Anthropogenic Climate Change?, B. Am. Meteorol. Soc., 92, 39-46, 2011.

Canadell, J. G., Le Quere, C., Raupach, M. R., Field, C. B., Buitenhuis, E. T., Ciais, P., Conway, T. J., Gillett, N. P., Houghton, R. A., and Marland, G.: Contributions to accelerating atmospheric $\mathrm{CO}_{2}$ growth from economic activity, carbon intensity, and efficiency of natural sinks, P. Natl. Acad. Sci., 104, 1886618870, 2007.

Cox, P. M., Betts, R. A., Jones, C. D., Spall, S. A., and Totterdell, I. J.: Acceleration of global warming due to carbon-cycle feedbacks in a coupled climate model, Nature, 408, 184-187, 2000.

Dimitropoulos, J.: Energy productivity improvements and the rebound effect: An overview of the state of knowledge, Energy Policy, 35, 6354-6363, 2007.

Etheridge, D. M., Steele, L. P., Langenfelds, R. L., Francey, R. J., Barnola, J., and Morgan, V. I.: Natural and anthropogenic changes in atmospheric $\mathrm{CO}_{2}$ over the last 1000 years from air in Antarctic ice and firn, J. Geophys. Res., 101, 4115-4128, 1996.

Flückiger, J., Monnin, E., Stauffer, B., Schwander, J., Stocker, T. F., Chappellaz, J., Raynaud, D., and Barnola, J.: High-resolution Holocene $\mathrm{N}_{2} \mathrm{O}$ ice core record and its relationship with $\mathrm{CH}_{4}$ and $\mathrm{CO}_{2}$, Global Biogeochem. Cy., 16, 010000-1, 2002.

Garrett, T. J.: Are there basic physical constraints on future anthropogenic emissions of carbon dioxide?, Clim. Change, 3, 437455, 2011.

Georgescu-Roegen, N.: Valuing the Earth: Economics, Ecology, Ethics, chap. The entropy law and the economic problem, MIT Press, 75-88, 1993.

Hansen, J., Sato, M., Ruedy, R., Kharecha, P., Lacis, A., Miller, R., Nazarenko, L., Lo, K., Schmidt, G. A., Russell, G., Aleinov, I., Bauer, S., Baum, E., Cairns, B., Canuto, V., Chandler, M., Cheng, Y., Cohen, A., Del Genio, A., Faluvegi, G., Fleming, E., Friend, A., Hall, T., Jackman, C., Jonas, J., Kelley, M., Kiang, N. Y., Koch, D., Labow, G., Lerner, J., Menon, S., Novakov, T., Oinas, V., Perlwitz, Ja., Perlwitz, Ju., Rind, D., Romanou, A., Schmunk, R., Shindell, D., Stone, P., Sun, S., Streets, D., Tausnev, N., Thresher, D., Unger, N., Yao, M., and Zhang, S.: Dangerous human-made interference with climate: a GISS modelE study, Atmos. Chem. Phys., 7, 2287-2312, doi:10.5194/acp-72287-2007, 2007.

Herring, H. and Roy, R.: Technological innovation, energy efficiency design and the rebound effect, Technovation, 27, 194203, 2007.

House of Lords, H.: Second Report: Energy Efficiency, Session 2005-2006, House of Lords Select Committee on Science and Technology, London, 2006.

Hsiang, S. M., Meng, K. C., and Cane, M. A.: Civil conflicts are associated with the global climate, Nature, 476, 438-441, 2011.

IPCC: Climate Change 2007 - The Physical Basis, Cambridge University Press, 2007a.
IPCC: Climate Change 2007 - Impacts, Adaption and Vulnerability, Cambridge University Press, 2007b.

Jevons, W. S.: The Coal Question, Macmillan and Co., 1865.

Joos, F., Bruno, M., Fink, R., Siegenthaler, U., Stocker, T. F., Le Quéré, C., and Sarmiento, J. L.: An efficient and accurate representation of complex oceanic and biospheric models of anthropogenic carbon uptake, Tellus B, 48, 397-417, 1996.

Keeling, C. D. and Whorf, T. P.: Trends: A Compendium of Data on Global Change, chap. Atmospheric $\mathrm{CO}_{2}$ records from sites in the SIO air sampling network, Carbon Dioxide Information Analysis Center, Oak Ridge National Laboratory, US Department of Energy, Oak Ridge, Tenn., USA, 2005.

Keller, K., Bolker, B., and Bradford, D.: Uncertain climate thresholds and optimal economic growth, J. Environ. Econ. Manage., 48, 723-741, 2004.

Le Quéré, C., Aumont, O., Bopp, L., Bousquet, P., Ciais, P., Francey, R., Heimann, M., Keeling, C. D., Keeling, R. F., Kheshgi, H., Peylin, P., Piper, S. C., Prentice, I. C., and Rayner, P. J.: Two decades of ocean $\mathrm{CO}_{2}$ sink and variability, Tellus B, 55, 649-656, 2003.

Le Quéré, C., Rödenbeck, C., Buitenhuis, E. T., Conway, T. J., Langenfelds, R., Gomez, A., Labuschagne, C., Ramonet, M., Nakazawa, T., Metzi, N., Gillett, N., and Heimann, M.: Saturation of the Southern Ocean $\mathrm{CO}_{2}$ Sink Due to Recent Climate Change, Science, 316, 1735-1738, 2007.

Leckebusch, G. C., Ulbrich, U., Fröhlich, L., and Pinto, J. G.: Property loss potentials for European midlatitude storms in a changing climate, Geophys. Res. Lett., 34, L5703, doi:10.1029/2006GL027663, 2007.

Liou, K.: An Introduction to Atmospheric Radiation, International Geophysics Series, Academic Press, 2002.

Lobell, D. B., Schlenker, W., and Costa-Roberts, J.: Climate trends and global crop production since 1980, Science, 333, 616-620, doi:10.1126/science.1204531, 2011.

Lotka, A. J.: Contribution to the energetics of evolution, P. Natl. Acad. Sci., 8, 147-151, 1922.

Maddison, A.: The World Economy: Historical Statistics, OECD, 2003.

Manning, M. R., Edmonds, J., Emori, S., Grubler, A., Hibbard, K., Joos, F., Kainuma, M., Keeling, R. F., Kram, T., Manning, A. C., Meinshausen, M., Moss, R., Nakicenovic, N., Riahi, K., Rose, S. K., Smith, S., Swart, R., and van Vuuren, D. P.: Misrepresentation of the IPCC $\mathrm{CO}_{2}$ emission scenarios, Nat. Geosci., 3, 376-377, 2010.

Marland, G., Boden, T. A., and Andres, R. J.: Trends: A Compendium of Data on Global Change, chap. Global, Regional, and National $\mathrm{CO}_{2}$ Emissions, Carbon Dioxide Information Analysis Center, Oak Ridge National Laboratory, US Department of Energy, Oak Ridge, Tenn., USA, 2007.

Mastrandrea, M. D. and Schneider, S. H.: Probabilistic integrated assessment of "dangerous" climate change, Science, 304, 571575, 2004.

Murphy, D. J. and Hall, C. A. S.: Year in review-EROI or energy return on (energy) invested, Ann. New York Acad. Sci., 1185, 102-118, doi:10.1111/j.1749-6632.2009.05282.x, 2010.

Nordhaus, W. D.: Economic aspects of global warming in a postCopenhagen environment, P. Natl. Acad. Sci., 107, 1172111726, 2010. 
Nordhaus, W. D. and Boyer, J.: Warming the World: Economic Models of Global Warming, MIT Press, Cambridge, USA, 2000.

Owen, D.: The efficiency dilemma, The New Yorker, 78-85, 2010.

Pacala, S. and Socolow, R.: Stabilization Wedges: Solving the Climate Problem for the Next 50 Years with Current Technologies, Science, 305, 968-972, 2004.

Parkin, M.: The New Palgrave Dictionary of Economics, 2nd Edn., chap. Inflation, Palgrave Macmillan, 2008.

Patz, P. A., Campbell-Lendrum, D., Holloway, T., and Foley, J. A.: Impact of regional climate change on human health, Nature, 438, 310-317, 2005.

Pielke, R. J., Gratz, J., Landsea, C., Collins, D., Saunders, M., and Musulin, R.: Normalized hurricane damage in the United States: 1900-2005, Nat. Hazards Rev., 9, 29-42, 2008.

Raupach, M. R., Marland, G., Ciais, P., Le Quéré, C., Canadell, J. G., Klepper, G., and Field, C.: Global and regional drivers of accelerating $\mathrm{CO}_{2}$ emissions, P. Natl. Acad. Sci., 104, 1028810293, 2007.

Sarel, M.: Nonlinear effects of inflation on economic growth, IMF Staff Papers, 43, 199-215, 1996.

Saunders, H. D.: A view from the macro side: rebound, backfire, and Khazzoom-Brookes, Energy Policy, 28, 439-449, 2000.

Sherwood, S. C. and Huber, M.: An adaptability limit to climate change due to heat stress, P. Natl. Acad. Sci., 107, 9552-9555, 2010 .
Solomon, S., Plattner, G., Knutti, R., and Friedlingstein, P.: Irreversible climate change due to carbon dioxide emissions, P. Natl. Acad. Sci., 106, 1704-1709, 2009.

Solow, R. M.: A contribution to the theory of economic growth, Q. J. Econ., 1970, 65-94, 1956.

Sorrell, S.: The Rebound Effect, Tech. rep., UKERC, 2007.

Sorrell, S., Speirs, J., Bentley, R., Brandt, A., and Miller, R.: Global oil depletion: A review of the evidence, Energy Policy, 38, 52905295, 2010.

Trenberth, K. E.: Seasonal variations in global sea level pressure and the total mass of the atmosphere, J. Geophys. Res., 86, 52385246, 1981.

United Nations: United Nations Statistical Databases, unstats.un. org/unsd/snaama (last access: January 2011), 2010.

Vermeer, M. and Rahmstorf, S.: Global sea level linked to global temperature, P. Natl. Acad. Sci., 106, 21527-21532, 2009.

Warr, B. and Ayres, R.: REXS: A forecasting model for assessing the impact of natural resource consumption and technological change on economic growth, Struct. Change Econ. Dyn., 17, 329-378, 2006.

Wigley, T.: The pre-industrial carbon dioxide level, Climatic Change, 5, 315-320, doi:10.1007/BF02423528, 1983. 